\title{
2',4'-dihydroxychalcone, a flavonoid isolated from Herba oxytropis, suppresses PC-3 human prostate cancer cell growth by induction of apoptosis
}

\author{
YUQING SHENG, MINGCHANG ZOU, YAN WANG and QIHENG LI \\ Department of Pharmacy, The First People's Hospital of Zhenjiang, Zhenjiang, Jiangsu 212002, P.R. China
}

Received October 26, 2014; Accepted September 14, 2015

DOI: $10.3892 / 01.2015 .3795$

\begin{abstract}
Natural products are a promising source for the development of novel cancer therapies, due to their potential effectiveness and low toxicity profiles. As a main component of Herba oxytropis, 2',4'-dihydroxychalcone (TFC) is known to demonstrate anti-tumor activity in vitro. In the present study, TFC was found to potently inhibit proliferation and induce apoptosis in PC-3 human prostate cancer cells in a dose-dependent manner. The results demonstrated that the induction of apoptosis is associated with cell cycle arrest at the G0/G1 phase and activation of caspase-3/-7. Additional mechanistic studies of two biomarkers, phosphatase and tensin homolog (PTEN) and cyclin-dependent kinase inhibitor 1B ( $\left.\mathrm{p} 27^{\mathrm{Kipl}}\right)$, in prostate cancer revealed that TFC treatment significantly upregulated the expression of PTEN and $\mathrm{p} 27^{\mathrm{Kip} 1}$. The findings of the present study indicate that TFC-induced apoptosis in PC-3 cells via upregulation of PTEN and p27 $7^{\text {Kipl, }}$, which results in cell cycle arrest in G0/G1 phase, activation of caspase-3/-7 and induction of apoptosis. Therefore, TFC may be a potential compound for human prostate cancer therapy.
\end{abstract}

\section{Introduction}

Prostate cancer is the second most frequently diagnosed cancer and the sixth leading cause of cancer-associated mortality in males worldwide, accounting for $14 \%(903,500)$ of total new cancer cases and $6 \%(258,400)$ of total cancer mortalities in males in 2008 (1). In the USA, prostate cancer alone accounted for $27 \%(233,000)$ of new cancer cases in men in 2014 , and the estimated number of prostate cancer mortalities was $~ 10 \%$ $(29,480)(2)$. Conventional therapy to eradicate tumor cells,

Correspondence to: Ms. Yuqing Sheng, Department of Pharmacy, The First People's Hospital of Zhenjiang, 8 Dianli Road, Zhenjiang, Jiangsu 212002, P.R. China

E-mail: sheng.yuqing@hotmail.com

Key words: 2',4'-dihydroxychalcone, prostate cancer, cell cycle, apoptosis, phosphatase and tensin homolog, cyclin-dependent kinase inhibitor 1B including surgery, chemotherapy, radiotherapy and hormonal treatments, has resulted in prolonged survival and successful treatment in certain patients (3). However, relapse and metastasis occur frequently, and are generally unresponsive to conventional therapy. Therefore, the development of novel agents for prostate cancer therapy is clinically important.

Natural products are a promising source for the development of novel cancer therapies, due to their potential effectiveness and low toxicity profiles (4). Flavonoids, a major class of natural products commonly found in fruits and vegetables, are demonstrably useful for the biologically active properties that inhibit tumor promotion and metastasis, such as apoptosis induction and cell cycle arrest in cancer cells (5-8).

One of the main components in Herba oxytropis is 2',4'-dihydroxychalcone (TFC) (9). Experimental studies have demonstrated the anti-tumor activity of TFC in cancer cells $(10,11)$. Previously, studies have demonstrated that TFC may induce the apoptosis of MGC-803 cells via downregulation of survivin mRNA expression $(9,12)$. However, the exact anti-tumor mechanism of TFC remains unclear.

In the present study, the authors investigated the anti-tumor effect of TFC on human prostate cancer cells. TFC was revealed to potently inhibit the proliferation of PC-3 human prostate cancer cells by induction of apoptosis. The results of the present study may provide a scientific explanation for the antitumor mechanism of TFC.

\section{Materials and methods}

Reagents. The reagent 2',4'-dihydroxychalcone (>95\% purity) was isolated from O.falcata herb, as described by Lu et al (13). The structure of TFC is exhibited in Fig. 1. The compound was dissolved in dimethyl sulfoxide (DMSO). The final concentration of DMSO was $<1 \%(\mathrm{v} / \mathrm{v})$. Ham's -12 Nutrient Mixture (F-12) was purchased from Life Technologies (Grand Island, NY, USA). Invitrogen fetal bovine serum was purchased from Thermo Fisher Scientific (Waltham, MA, USA). Cell counting kit (CCK-8) was purchased from Beyotime Institute of Biotechnology (Haimen, Jiangsu, China). Fluorescein isothiocyanate (FITC) Annexin V Apoptosis Detection kit and Cycletest plus DNA Reagent kit were obtained from BD Pharmingen (San Diego, CA, USA). Other chemicals were of analytical grade from commercial suppliers (Sinopharm Chemical Reagent Co., Ltd., Nanjing, China). 
Cell culture. The human prostate cancer PC-3 cell line was purchased from the Cell Bank of China Academy of Sciences (Shanghai, China) and maintained in F-12 culture medium containing $10 \%$ fetal bovine serum, $100 \mathrm{U} / \mathrm{ml}$ penicillin and $100 \mathrm{U} / \mathrm{ml}$ streptomycin, at $37^{\circ} \mathrm{C}$ and supplied with $95 \%$ room air and $5 \% \mathrm{CO}_{2}$.

Cell viability assay. PC-3 cells in the exponential phase of growth were placed in a 96-well plate $(5,000$ cells/well). Following a 4-h incubation period, the cells were treated with compounds or with the vehicle (vehicle control, $1 \%$ DMSO) for $24 \mathrm{~h}$. Then $10 \mu \mathrm{l}$ of CCK- 8 was added and the plates were incubated for another $4 \mathrm{~h}$. The absorbance at $450 \mathrm{~nm}$ was recorded by a Benchmark ${ }^{\mathrm{TM}}$ Plus microplate reader (Bio-Rad Laboratories, Hercules, CA, USA).

Cell morphology. The PC-3 cells were incubated with or without TFC for $24 \mathrm{~h}$ in a $5 \% \mathrm{CO}_{2}$ incubator at $37^{\circ} \mathrm{C}$. Then, the cells were observed for morphological changes using an Eclipse TE2000-U inverted microscope (Nikon Instruments, Melville, NY, USA) and images were captured.

Flow cytometry analysis to determine cell cycle distribution and apoptosis. Flow cytometry was used to analyze the cell cycle distribution and apoptosis subsequent to treatment with TFC. Briefly, for the apoptosis analysis assay, the PC-3 cells were placed in a 6 -well plate $\left(1 \times 10^{6}\right.$ cells/well $)$ and treated with various doses of TFC for $24 \mathrm{~h}$. The cells were then collected, washed with phosphate-buffered saline (PBS) and re-suspended in $1 \mathrm{X}$ binding buffer. FITC Annexin V and propidium iodide (PI) reagent were added and staining occurred for $15 \mathrm{~min}$ prior to flow cytometry analysis. For the cell cycle analysis assay performed subsequent to TFC treatment, the cells were collected and fixed with $70 \%$ ethanol overnight. The cells were then handled according to the manufacturer's instructions with Cycletest plus DNA Reagent kit, prior to analysis by flow cytometry. The cells in the G0/G1, S and $\mathrm{G} 2 / \mathrm{M}$ phases were gated out as appropriate.

Western blot analysis. The PC-3 cells were treated with TFC for $24 \mathrm{~h}$ and the treated cells were collected, washed three times with PBS and lysed in cell lysis buffer. The cell lysates were separated on a $15 \%$ polyacrylamide gel and transferred to a polyvinyl difluoride membrane (EMD Millipore, Billerica, MA, USA). Subsequent to blocking with Block Ace (AppliChem GmbH, Darmstadt, Germany) for $4 \mathrm{~h}$ at room temperature, the membrane was incubated overnight with primary antibodies, and then for $2 \mathrm{~h}$ with secondary antibodies. All antibodies were obtained from Cell Signaling Technology (Danvers, MA, USA). The following rabbit anti-human primary antibodies were used for western blot analysis: Anti-p27 ${ }^{\mathrm{Kip} 1}$ (monoclonal; clone, D69C12; cat no. 3686); anti-PTEN (monoclonal; clone, D4.3; cat no. 9188); anti-caspase-7 (polyclonal; cat no. 9492); anti-caspase-3 (monoclonal; clone, 8G10; cat no. 9665); and anti- $\beta$-actin (monoclonal; clone, 13E5; cat no. 4970). Anti-rabbit IgG conjugated to horseradish peroxidase (cat no. 7074) was used as the secondary antibody. The primary antibodies were used at a dilution of 1:1,000. The secondary antibodies were used at a dilution of 1:3,000 and visualized

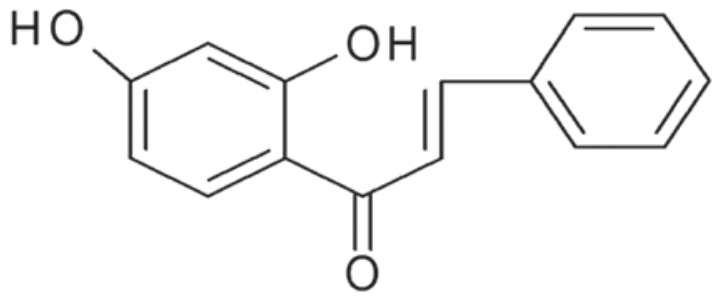

Figure 1. Structure of 2',4'-dihydroxychalcone.

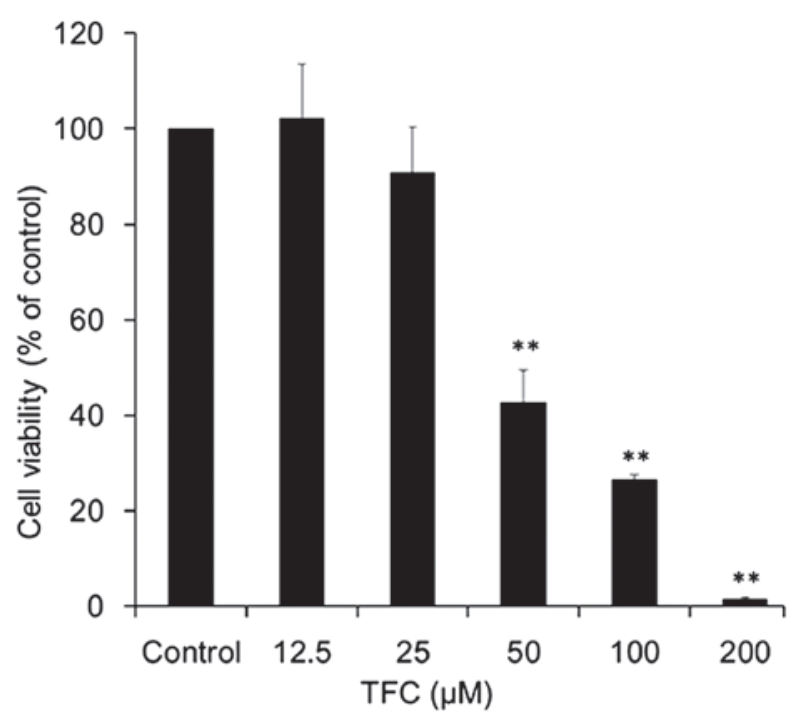

Figure 2. Effect of TFC on the proliferation of PC-3 cells. PC-3 cells were treated with TFC $(12.5,25,50,100$ and $200 \mu \mathrm{M})$ for $24 \mathrm{~h}$. Cell viability was determined by cell counting kit- 8 assay and the findings were expressed as the mean \pm standard deviation of three separate experiments. Significant differences from the untreated control are indicated by ${ }^{*} \mathrm{P}<0.05$ and ${ }^{* *} \mathrm{P}<0.01$. TFC, 2',4'-dihydroxychalcone.

with an enhanced chemiluminescence system (Amersham Imager 600; GE Healthcare Life Sciences, Little Chalfont, UK).

Statistical analysis. Statistical analysis was performed using SPSS version 13.0 software (SPSS, Inc., Chicago, IL, USA). The results were expressed as the mean \pm standard deviation. $\mathrm{P}<0.05$ or $\mathrm{P}<0.01$ was considered to indicate a statistically significant difference.

\section{Results}

TFC inhibits PC-3 cell growth in a dose-dependent manner. The CCK- 8 assay was used as an indirect measure to determine the viability of PC-3 cells exposed to TFC. TFC significantly suppressed the cell viability of PC- 3 cells in a dose-dependent manner (Fig. 2). The cell viability was reduced to $90.81,42.51$, 26.52 and $1.51 \%$ when cells were treated with $25,50,100$ and $200 \mu \mathrm{M}$ TFC, respectively. The half maximal inhibitory concentration $\left(\mathrm{IC}_{50}\right)$ was $53.82 \mu \mathrm{M}$. Morphological changes were observed using microscopy (Fig. 3). The PC-3 cells treated with TFC for $24 \mathrm{~h}$ exhibited marked morphological changes. TFC caused individual cells to shrink and separate from neighboring cells. The cells appeared refringent and finally detached from the monolayer by TFC administration. 
A

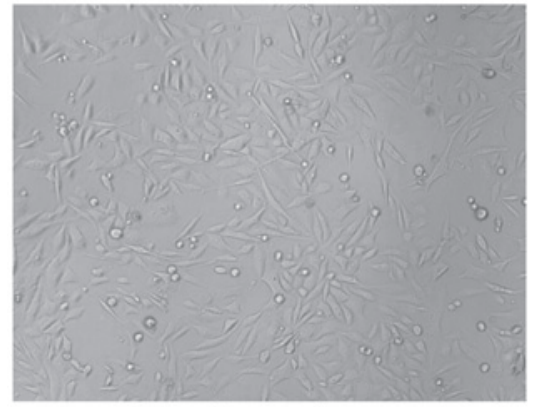

Control

C

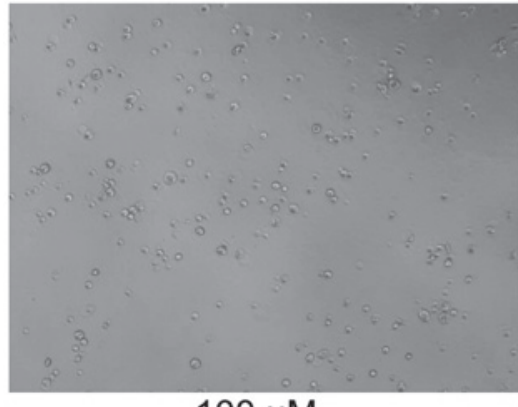

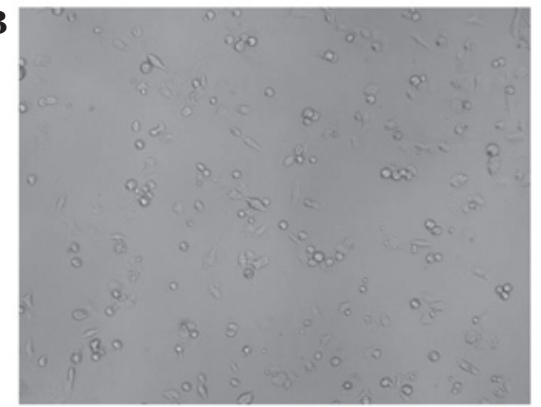

$50 \mu \mathrm{M}$

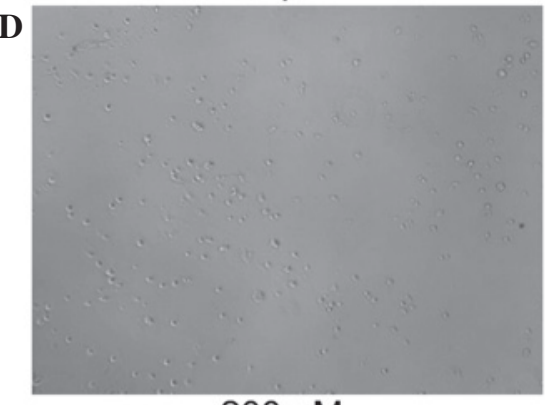

$200 \mu \mathrm{M}$

Figure 3. Morphological changes in PC-3 cells treated with TFC for $24 \mathrm{~h}$ (magnification, $\mathrm{x} 100$ ). (A) Control cells. (B) Cells treated with $50 \mu \mathrm{M}$ TFC. (C) Cells treated with $100 \mu \mathrm{M}$ TFC. (D) Cells treated with $200 \mu \mathrm{M}$ TFC. The cell morphology was observed using microscopy. TFC, 2',4'-dihydroxychalcone.

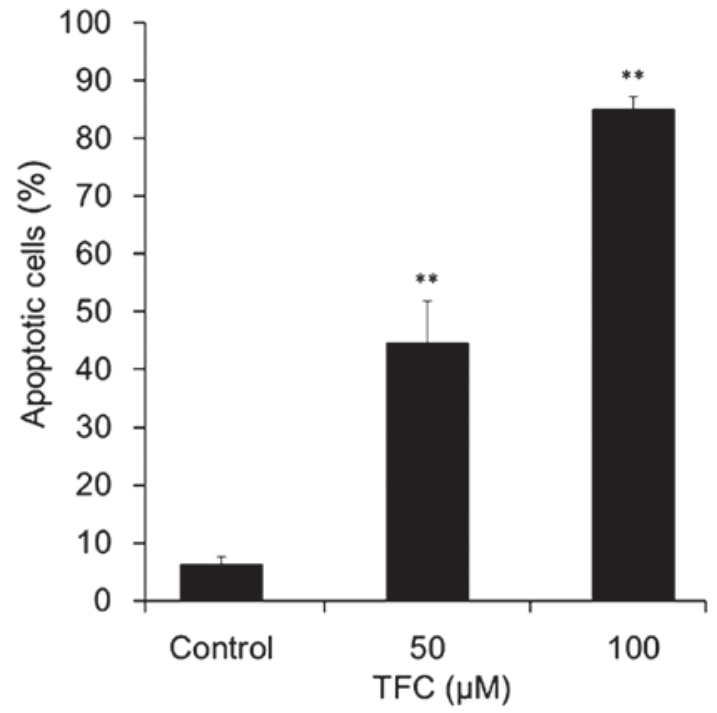

Figure 4. Flow cytometry analysis of the effect of TFC on the induction of apoptosis in PC-3 cells. The PC-3 cells were treated with $1 \%$ dimethylsulfoxide or 50 or $100 \mu \mathrm{M} \mathrm{TFC}$ for $24 \mathrm{~h}$. The treated cells were collected, washed with phosphate-buffered saline and resuspended in $1 \mathrm{X}$ binding buffer. Fluorescein isothiocyanate Annexin $\mathrm{V}$ and propidium iodide reagent were added, and staining occurred for 15 min prior to flow cytometry analysis. The data were expressed as the mean \pm standard deviation of three separate experiments. Significant differences from the untreated control are indicated by ${ }^{*} \mathrm{P}<0.05$ and ${ }^{* *} \mathrm{P}<0.01$. TFC, $2^{\prime}, 4^{\prime}$-dihydroxychalcone.

TFC induces apoptosis in PC-3 cells. To determine whether the reduction of cell viability in PC-3 cells was associated with the induction of apoptosis, flow cytometry analysis was used to assess the number of apoptotic cells following TFC treatment. Apoptotic cells were significantly increased in a dose-dependent manner when compared with the control group (Fig. 4). The percentage of apoptotic cells reached

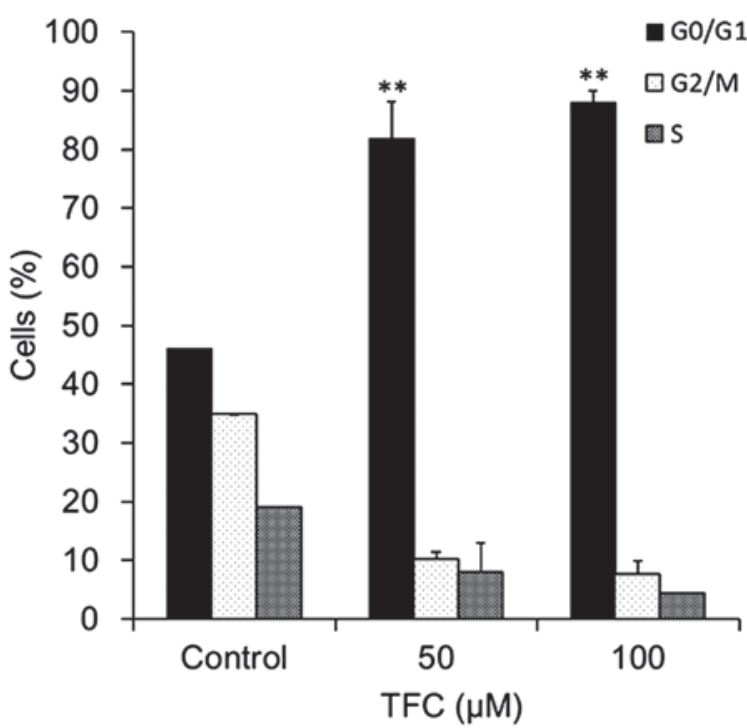

Figure 5. Effect of TFC on the cell cycle distribution in PC-3 cells, as determined by flow cytometry analysis. The PC-3 cells were treated with $1 \%$ dimethylsulfoxide or 50 or $100 \mu \mathrm{M}$ TFC for $24 \mathrm{~h}$. Following treatment, the cells were collected, washed with PBS and fixed with $70 \%$ alcohol overnight. The cells were then handled using the Cycletest plus DNA Reagent kit, according to the manufacturer's protocol, prior to analysis by flow cytometry. Cells in the G0/G1, S and G2/M phases were gated out as appropriate. Significant differences from the untreated control are indicated by "P $<0.05$ and ${ }^{* *} \mathrm{P}<0.01$. TFC, 2',4'-dihydroxychalcone.

$44.58 \pm 7.19$ and $85.05 \pm 2.14 \%$ when treated with 50 and $100 \mu \mathrm{M}$ TFC, respectively. These results demonstrated that TFC inhibited the proliferation of PC-3 cells by inducing apoptosis.

TFC arrests the cell cycle of PC-3 cells in the G0/G1 phase. Cell cycle distribution was assessed by flow cytometry. The results demonstrated that TFC treatment caused G0/G1 phase 
A

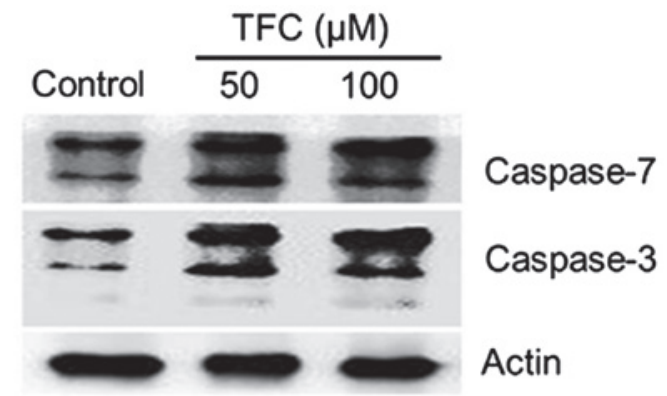

B

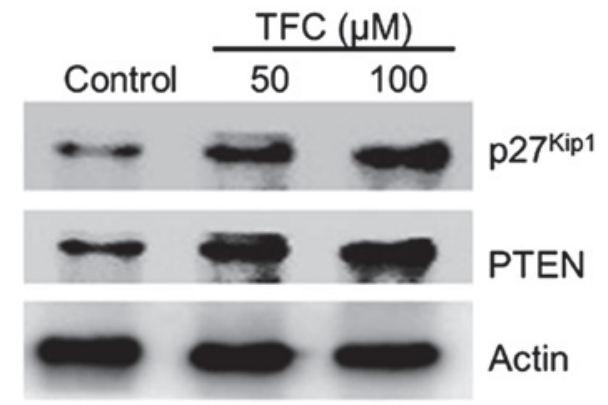

Figure 6. (A) Effect of TFC on the activation of caspase-3/-7 in PC-3 cells. The cells were treated with TFC for $24 \mathrm{~h}$. The treated cells were collected, washed with PBS and lysed in cell lysis buffer. Cell lysates were collected and subjected to western blot analysis to detect the expression of associated proteins. The results were representative of at least three independent experiments with similar results. (B) Expression of p27 $7^{\mathrm{Kip} 1}$ and PTEN in PC-3 cells. The cells were treated with TFC for $24 \mathrm{~h}$. Treated cells were collected, washed with PBS and lysed in cell lysis buffer. Cell lysates were collected and subjected to western blot analysis to detect the expression of the $\mathrm{p} 27^{\mathrm{Kip} 1}$ and PTEN proteins. The results were representative of at least three independent experiments with similar results. TFC, 2',4'-dihydroxychalcone; PBS, phosphate-buffered saline; PTEN, phosphatase and tensin homolog; p27 ${ }^{\text {Kipl }}$, cyclin-dependent kinase inhibitor $1 \mathrm{~B}$.

cell cycle arrest in PC-3 cells (Fig. 5). The percentage of cells in the G0/G1 phase significantly increased between $46.06 \%$ in the cells not treated with TFC and $89.87 \%$ in cells treated with $100 \mu \mathrm{M}$ TFC. These results indicated that TFC induced apoptosis in PC-3 cells by arresting the cell cycle in the G0/G1 phase.

TFC increases caspase-3/7 activation in PC-3 cells. Caspases are crucial mediators of programmed cell death, termed apoptosis (14). Out of these mediators, caspase- 3 and caspase-7 are responsible for the proteolytic cleavage of numerous key proteins, including adenosine diphosphate (ADP)-ribose polymerase and poly(ADP-ribose) polymerase, that induce cell apoptosis (14). In the present study, TFC treatment significantly increased the activation of caspase-3 and -7 (Fig. 6A), demonstrating the importance of caspases in the induction of apoptosis.

TFC upregulates PTEN and $p 27^{\text {Kipl }}$ expression in PC-3 cells. The expression levels of the cyclin-dependent kinase inhibitor $\mathrm{p} 27^{\mathrm{Kipl}}$ have been revealed to be a reliable prognostic marker in prostate cancer, as low or absent expression of $\mathrm{p} 27^{\mathrm{Kipl}}$ correlates with poor prognosis (15). In addition, PTEN, a tumor-suppressor gene and one of the most promising biomarkers for prostate cancer, also acts as a valid and accurate tool for the prediction of prognosis and support of clinical decisions $(16,17)$. To determine the effect of TFC on these biomarkers in prostate cancer, western blot analysis was performed to assess the effect of TFC on the expression of p2 $7^{\text {Kipl }}$ and PTEN in PC-3 cells. Notably, the expression of PTEN and $\mathrm{p} 27^{\mathrm{Kip} 1}$ was significantly upregulated subsequent to treatment with TFC (Fig. 6B).

\section{Discussion}

Apoptosis, an ordered and orchestrated cellular process that occurs in physiological and pathological conditions, plays an important role in the treatment of cancer and is a popular target of numerous treatment strategies (18). In general, drug-induced apoptosis is a major advancement for the treatment of cancer (19). In the present study, it was demonstrated that TFC may effectively inhibit the growth of PC-3 cells, induce apoptosis, activate caspase-3/-7 and block the cell cycle in the G0/G1 phase. TFC was revealed to be a potential compound for prostate cancer therapy.

Expression levels of $\mathrm{p} 27^{\mathrm{Kipl}}$ have been revealed as reliable prognostic markers in prostate cancer (15). Studies have linked loss of $\mathrm{p} 27^{\mathrm{Kip} 1}$ expression with the development and progression of prostate carcinoma, and animal models have implicated this gene in the development of prostate carcinoma (20-23). In addition, $\mathrm{p} 27^{\mathrm{Kip} 1}$ is also a cell-cycle regulatory protein that interacts with cyclin-dependent kinase (CDK) 2 and CDK4, inhibiting cell cycle progression at the G1 phase (24). An increase in $\mathrm{p} 27^{\mathrm{Kipl}}$ protein expression causes proliferating cells to exit from the cell cycle, whereas a decrease in $\mathrm{p} 27^{\text {Kipl }}$ protein expression promotes quiescent cells to resume cell proliferation (25). By contrast, PTEN, a tumor-suppressor gene, is one of the most promising biomarkers for prostate cancer $(16,17)$. PTEN is hypothesized to operate via the action of its phosphatase protein product. This phosphatase is involved in the regulation of the cell cycle and prevents cells from growing and dividing rapidly (26). The expression of PTEN can inhibit cell cycle progression, induce G0/G1 cell cycle arrest, inhibit cell migration and induce apoptosis (27-30). Consistent with these previous findings, the expression of $\mathrm{p} 27^{\mathrm{Kipl}}$ and PTEN was significantly upregulated with TFC treatment in PC-3 cells in the present study (Fig. 6B). The upregulation of p27 ${ }^{\mathrm{Kipl}}$ and PTEN may contribute to the cell cycle arrest in the G0/G1 phase and the induction of apoptosis. Furthermore, previous studies demonstrated that PTEN regulates the ubiquitin-dependent degradation of the CDK inhibitor $\mathrm{p} 27^{\mathrm{Kip} 1}$ through the Skp, Cullin, F-box containing ubiquitin E3 ligase complex (31). It is possible that the activation of $\mathrm{p} 27^{\mathrm{Kipl}}$ may be due to the upregulation of PTEN in PC-3 cells. However, numerous studies are required to test this hypothesis.

In conclusion, the present study demonstrated that TFC treatment in PC-3 cells can upregulate the expression of p2 $7^{\mathrm{Kip} 1}$ and PTEN, block the cell cycle in the G0/G1 phase and induce apoptosis. However, additional studies are required to determine the exact mechanisms of action and to explore genetic and signal transduction pathways. Finally, the present results revealed that TFC may be a potential compound for prostate cancer therapy.

\section{Acknowledgements}

This study was kindly supported by the Zhenjiang Science and Technology Project (grant no. SH2012040). 


\section{References}

1. Jemal A, Bray F, Center MM, Ferlay J, Ward E and Forman D: Global cancer statistics. CA Cancer J Clin 61: 69-90, 2011.

2. Siegel R, Ma J, Zou Z and Jemal A: Cancer statistics, 2014. CA Cancer J Clin 64: 9-29, 2014.

3. Brawley OW, Barnes S and Parnes $\mathrm{H}$ : The future of prostate cancer prevention. Ann Ny Acad Sci 952: 145-152, 2001.

4. Crowell JA: The chemopreventive agent development research program in the Division of Cancer Prevention of the US National Cancer Institute: An overview. Eur J Cancer 41: 1889-1910, 2005

5. Yue R, Li B, Shen Y, Zeng H, Li B, Yuan H, He Y, Shan L and Zhang W: 6-C-methyl flavonoids isolated from Pinus densata inhibit the proliferation and promote the apoptosis of the HL-60 human promyelocytic leukaemia cell line. Planta Med 79: 1024-1030, 2013

6. Costa SS, Couceiro JN, Silva IC, Malvar Ddo C, Coutinho MA Camargo LM, Muzitano MF and Vanderlinde FA: Flavonoids in the therapy and prophylaxis of flu: A patent review. Expert Opin Ther Pat 22: 1111-1121, 2012

7. Wang Y, Chen Y, Wang J, Chen J, Aggarwal BB, Pang X and Liu M: Xanthohumol, a prenylated chalcone derived from hops, suppresses cancer cell invasion through inhibiting the expression of CXCR4 chemokine receptor. Curr Mol Med 12: 153-162, 2012

8. Vidya Priyadarsini R, Senthil Murugan R, Maitreyi S, Ramalingam K, Karunagaran D and Nagini S: The flavonoid quercetin induces cell cycle arrest and mitochondria-mediated apoptosis in human cervical cancer (HeLa) cells through p53 induction and NF- $\mathrm{BB}$ inhibition. Eur J Pharmacol 649: 84-91, 2010.

9. Lou CH, Yang GM, Cai H, Zou M, Xu Z, Li Y, Zhao F, Li W Tong L, Wang $\mathrm{M}$ and Cai B: 2',4'-Dihydroxychalcone-induced apoptosis of human gastric cancer MGC-803 cells via down-regulation of survivin mRNA. Toxicol In Vitro 24: 1333-1337, 2010.

10. Chen JJ, Lee HH, Duh CY and Chen IS: Cytotoxic chalcones of flavonoids from the leaves of Muntingia calabura. Planta Med 71: 970-973, 2005

11. Pouget C, Lauthier F, Simon A, Fagnere C, Basly JP, Delage C and Chulia AJ: Flavonoids: Structural requirements for antiproliferative activity on breast cancer cells. Bioorg Med Chem Lett 11: 3095-3097, 2001

12. Lou C, Wang M, Yang G, Cai H, Li Y, Zhao F, Yang H, Tong L and Cai B: Preliminary studies on anti-tumor activity of 2',4'-dihydroxychalcone isolated from Herba oxytropis in human gastric cancer MGC-803 cells. Toxicol In Vitro 23: 906-910, 2009.

13. Lu F and Xu XJ: Studies on flavonoids of Oxytropis falcata Zhongguo Zhong Yao Zazhi 32: 318-320, 2007 (In Chinese).

14. Porter AG and Jänicke RU: Emerging roles of caspase-3 in apoptosis. Cell Death Differ 6: 99-104, 1999.

15. Macri E and Loda M: Role of $\mathrm{p} 27$ in prostate carcinogenesis. Cancer Metastasis Rev 17: 337-344, 1998.

16. Pourmand G, Ziaee AA, Abedi AR, Mehrsai A, Alavi HA, Ahmadi A and Saadati HR: Role of PTEN gene in progression of prostate cancer. Urol J 4: 95-100, 2007.

17. Liu Y,Hegde P,Zhang F, Hampton G and Jia S: Prostate cancer - a biomarker perspective. Front Endocrinol (Lausanne) 3: 72, 2012
18. Wong RS: Apoptosis in cancer: From pathogenesis to treatment. J Exp Clin Canc Res 30: 87, 2011.

19. Saddoughi SA, Song P and Ogretmen B: Roles of bioactive sphingolipids in cancer biology and therapeutics. Subcell Biochem 49: 413-440, 2008

20. Guo YP, Sklar GN, Borkowski A and Kyprianou N: Loss of the cyclin-dependent kinase inhibitor p27(Kip1) protein in human prostate cancer correlates with tumor grade. Clin Cancer Res 3 2269-2274, 1997

21. Yang RM, Naitoh J, Murphy M, Wang HJ, Phillipson J, deKernion JB, Loda M and Reiter RE: Low p27 expression predicts poor disease-free survival in patients with prostate cancer. J Urol 159: 941-945, 1998.

22. Tsihlias J, Kapusta LR, DeBoer G, Morava-Protzner I, Zbieranowski I, Bhattacharya N, Catzavelos GC, Klotz LH, and Slingerland JM: Loss of cyclin-dependent kinase inhibitor $\mathrm{p} 27 \mathrm{Kip} 1$ is a novel prognostic factor in localized human prostate adenocarcinoma. Cancer Res 58: 542-548, 1998.

23. Cordon-Cardo C, Koff A, Drobnjak M, Capodieci P, Osman I, Millard SS, Gaudin PB, Fazzari M, Zhang ZF, Massague J and Scher HI: Distinct altered patterns of p27Kip1 gene expression in benign prostatic hyperplasia and prostatic carcinoma. J Natl Cancer Inst 90: 1284-1291, 1998.

24. Kato JY, Matsuoka M, Polyak K, Massague J and Sherr CJ: Cyclic AMP-induced G1 phase arrest mediated by an inhibitor (p27Kip1) of cyclin-dependent kinase 4 activation. Cell 79: 487-496, 1994.

25. Le XF, Claret FX, Lammayot A, Tian L, Deshpande D, LaPushin R, Tari AM and Bast RC Jr: The role of cyclin-dependent kinase inhibitor p27Kip1 in anti-HER2 antibody-induced G1 cell cycle arrest and tumor growth inhibition. J Biol Chem 278: 23441-23450, 2003

26. Chu EC and Tarnawski AS: PTEN regulatory functions in tumor suppression and cell biology. Med Sci Monit 10: RA235-RA241, 2004.

27. Furnari FB, Huang HJ and Cavenee WK: The phosphoinositol phosphatase activity of PTEN mediates a serum-sensitive G1 growth arrest in glioma cells. Cancer Res 58: 5002-5008, 1998.

28. Persad S, Attwell S, Gray V, Delcommenne M, Troussard A, Sanghera J and Dedhar S: Inhibition of integrin-linked kinase (ILK) suppresses activation of protein kinase B/Akt and induces cell cycle arrest and apoptosis of PTEN-mutant prostate cancer cells. Proc Natl Acad Sci USA 97: 3207-3212, 2000.

29. Backman SA, Ghazarian D, So K, Sanchez O, Wagner KU, Hennighausen L, Suzuki A, Tsao MS, Chapman WB, Stambolic V and Mak TW: Early onset of neoplasia in the prostate and skin of mice with tissue-specific deletion of Pten. Proc Natl Acad Sci USA 101: 1725-1730, 2004

30. Xie F, Su M, Qiu W, Zhang M, Guo Z, Su B, Liu J, Li X and Zhou L: Kaempferol promotes apoptosis in human bladder cancer cells by inducing the tumor suppressor, PTEN. Int J Mol Sci 14: 21215-21226, 2013.

31. Mamillapalli R, Gavrilova N, Mihaylova VT, Tsvetkov LM, Wu H, Zhang $\mathrm{H}$ and Sun H: PTEN regulates the ubiquitin-dependent degradation of the CDK inhibitor p27(Kip1) through the ubiquitin E3 ligase SCF(SKP2). Curr Biol 11: 263-267, 2001. 